\title{
Comparison of the prevalence of asthma among Asian and European children in Southampton
}

\author{
Catherine D Pararajasingam, Lara Sittampalam, Parvin Damani, Philip K Pattemore, \\ Stephen T Holgate
}

\begin{abstract}
Background Primary health care workers have reported an impression that asthma is commoner among Asian than European children, and a cross sectional survey was designed to compare the prevalence in Asian and European children.

Methods The survey was carried out in children aged 7-11 in eight primary schools in Southampton. Four schools contained predominantly children of European ancestry, two contained predominantly Asian children, and two contained a mixture of ethnic groups. Data were collected by means of parent completed questionnaire on recent asthma symptoms, diagnosis, morbidity, and treatment from 759 European and
\end{abstract} 274 Asian children.

Results The prevalence of reported wheeze in the previous 12 months was higher among European (19.6\%) than Asian children $(11.9 \%)$, as was the prevalence of a night cough (European $64 \cdot 2 \%$, Asian $42 \cdot 3 \%$ ). Although the prevalence of diagnosed asthma was higher in European (12\%) than Asian (6.2\%) children, a slightly higher proportion of Asian than European children with current wheeze had visited their doctor (European $66.9 \%$, Asian $78 \cdot 1 \%$, not significant) or been admitted to hospital for wheezing (European $4.8 \%$, Asian 6.5\%) in the previous 12 months.

Conclusions This study failed to demonstrate a higher prevalence of asthma among Asian than European children in Southampton.

Faculty of Medicine, University of Southampton Southampton C D Pararajasingam L Sittampalam P K Pattemore $S$ T Holgate

South West Hampshire Health Authority

P Damani

Address for reprint requests Professor S T Holgate

Medicine I, Level D, Centre Block, Southampton Genera Hospital, Southampton SO9 4XY

Accepted 28 January 1992
Over the past two decades comparisons of asthma prevalence in the United Kingdom among subjects of Asian and European ancestry have found a higher, ${ }^{1-3}$ lower, ${ }^{4-6}$ or similar ${ }^{7}$ prevalence of asthma among Asians. In one study subjects originating from different areas in India were found to have quite different rates of respiratory conditions. ${ }^{8}$ Studies of attendances at accident and emergency departments and of hospital admissions for respiratory disease including asthma have generally found higher rates among Asians than among Europeans. 259

The multicultural health adviser for the South West Hampshire Area Health Authority (PD) became concerned about reports from primary health care workers that asthma was being seen very commonly in Asian children. Previous studies in Southampton had examined predominantly European children, ${ }^{10}$ and there were few data on asthma among the Asian population. We report on a study to compare the prevalence of asthma symptoms, diagnosis, drug treatment, and morbidity between Asian and European children in Southampton.

\section{Subjects and methods}

Children aged 7 to 12 years in selected primary schools in Southampton were surveyed between November 1989 and April 1990. In mid-1988 the number of children in this age range in Southampton was estimated as 14000.

SUBJECTS

For the study to have $80 \%$ power required an estimated sample size of 350 children from each ethnic group, on the basis of the one sided alternative hypothesis that the true asthma prevalence was $13 \%$ in Europeans ${ }^{10}$ and $20 \%$ or higher in Asians. For convenience we decided to study all children in the desired age range in schools with a high proportion of Asian children in Southampton. Two schools with predominantly Asian children took part (a third school declined), as did two schools with a mixture of Asian and European children. Four predominantly European schools drawing from residential areas with a similar socioeconomic distribution to the other four schools were also chosen for comparison.

\section{QUESTIONNAIRE}

An English language questionnaire was designed containing 10 questions about the child's perceived race; symptoms, diagnosis, and treatment of asthma; and visits to the doctor, hospital admissions, and time off school because of asthma in the previous year. Two further questions asked the parents to write down the number of children in the home and the occupation of both parents. The questionnaire was designed to be simple, short, and unambiguous with no conditional skipped questions. The heading stated: "For questions 1-10, please tick the appropriate box, whichever is most suitable regarding your child." The question on wheezing was: "Within the last 12 months, my child had attacks of wheezing: [boxes] 0 times, 1-4 times, 5-12 times, more than 12 times." An accompanying explanatory letter included the following 
statement: "The word 'wheeze' in this questionnaire means noisy breathing with a whistling or squeaky sound coming from the chest."

The questionnaire (with explanatory letter) was delivered to the child at school to take home for completion by the parents. If any child did not return a completed questionnaire within a month of issue, a further questionnaire was issued, along with a parallel translation into the appropriate language group of the parents (Punjabi, Bengali, or Urdu) for Asian children in case language difficulty was the reason for non-return. Translators had difficulty with the word "wheeze" as there is no direct counterpart in any of the Asian languages. Thus it was by no means certain that answers based on the translation would be any more valid than answers to the English language questionnaire.

To assess repeatability the English questionnaire was reissued to one predominantly European and one predominantly Asian class (returned by 11/40 European and 12/18 Asian children). In a third, predominantly Asian class, the English questionnaire along with the appropriate language translation was issued on the second occasion (returned by $16 / 20$ children). The only questions which did not have a $90 \%$ or greater proportion in agreement concerned night cough in Europeans $(82 \%)$, exercise induced wheeze in Asians not given a translation (75\%), and current wheeze in Asian children given a translation (87.5\%). Questions concerning family size and occupation of the parents showed poor repeatability among Asians (percentage in agreement for occupation of father $58 \%$, and for occupation of mother $75 \%$ ).

\section{APPROVAL AND CONSENT}

The study was approved by the joint ethical subcommittee of the Southampton and South West Hampshire Health Authority and the Faculty of Medicine of the University of Southampton, by the Education Authority of Hampshire County Council, and by the principals of the schools concerned. Return of the completed questionnaire by the parents was deemed to represent consent to participation.

\section{DATA ANALYSIS AND DEFINITIONS}

Entered data were checked visually and by range check and analysed by SPSS-X.

Race was defined from the parents reply to the question: "What race is your child?"-the options being listed as European, Asian, and other. Children whose parents ticked the "other" box were excluded from the analysis. Socioeconomic group was defined on the basis of the father's occupation according to the registrar general's classification of occupations. Asthma prevalence was compared on the basis of wheeze reported in the previous 12 months ("current wheeze") and diagnosis reported by a general practitioner or physician.

\section{Results}

PARTICIPATION

The total number of Asian children available for study in Southampton did not reach the desired number for power calculations based on equal sample size, but European children were overrepresented in the sample. The questionnaire was initially delivered to 333 Asian and 1014 non-Asian children and reissued to 100 Asian children (91 with a translation) and 322 non-Asian children. In all, 274 questionnaires were returned by Asian children $(82.3 \%$ ) (including 39 children given a translation) and 811 by non-Asian children $(80.0 \%)$, of whom 759 were of European extraction (the remainder were excluded from the analysis). The eventual sampling ratios were estimated as $28 \%$ of the age specific Asian target population and $6 \%$ of the age specific European target population.

\section{CHARACTERISTICS OF PARTICIPANTS}

The distributions of participants in each ethnic group by age, sex, and socioeconomic group are compared in table 1. Age and sex distribution but not socioeconomic distribution were closely matched in the two ethnic groups. Among the 274 Asian participants $57.3 \%$ spoke Punjabi, 20.4\% Urdu, 10.6\% Bengali, and $5.5 \%$ Gujurati. Ten of the 591 European children $(2 \cdot 1 \%)$ were reported as having been born overseas, compared with 17 of the 144 Asian children $(11.9 \%)$. The proportion of children from families with more than four children was much higher among Asians $(50.4 \%$ of 252$)$ than Europeans (6.2\% of 735$)$.

ASTHMA SYMPTOMS, DIAGNOSIS, AND INDICES OF MORBIDITY IN THE PREVIOUS 12 MONTHS

The prevalences of reported wheezing, night cough, and diagnosed asthma were significantly higher among European children than among Asian children (table 2). Proportionately, almost twice as many European as Asian children had lost some time from school because of wheezing, and European children were also slightly more likely to have visited their doctor or been admitted to hospital for wheezing than Asian children. In spite of these differences, the proportion of children reported

Table 1 Characteristics of participants. Values are percentages

\begin{tabular}{|c|c|c|}
\hline & $\begin{array}{l}\text { European } \\
(n=759)\end{array}$ & $\begin{array}{l}\text { Asian } \\
(n=274)\end{array}$ \\
\hline \multicolumn{3}{|l|}{ Age (years): } \\
\hline 7 & $12 \cdot 5$ & 10.9 \\
\hline 8 & $22 \cdot 3$ & $24 \cdot 1$ \\
\hline 9 & $23 \cdot 6$ & $24 \cdot 1$ \\
\hline 10 & $22 \cdot 0$ & $16 \cdot 4$ \\
\hline 11 & $16 \cdot 2$ & $16 \cdot 4$ \\
\hline 12 & $3 \cdot 4$ & $8 \cdot 0$ \\
\hline \multicolumn{3}{|l|}{ Sex: } \\
\hline Male & $50 \cdot 3$ & $47 \cdot 4$ \\
\hline Female & $49 \cdot 7$ & $52 \cdot 6$ \\
\hline \multicolumn{3}{|c|}{ Socioeconomic group: } \\
\hline I & $12 \cdot 0$ & $2 \cdot 2$ \\
\hline II & $13 \cdot 2$ & $5 \cdot 8$ \\
\hline III Non-manual & $5 \cdot 3$ & $4 \cdot 0$ \\
\hline III Manual & $46 \cdot 8$ & $38 \cdot 7$ \\
\hline IV & $2 \cdot 0$ & $4 \cdot 0$ \\
\hline V & $3 \cdot 6$ & $1 \cdot 1$ \\
\hline Unemployed & $8 \cdot 4$ & $19 \cdot 7$ \\
\hline Not specified & $8 \cdot 8$ & $24 \cdot 5$ \\
\hline
\end{tabular}


Table 2 Asthma symptoms and indices of morbidity in previous 12 months. Values are percentages

\begin{tabular}{|c|c|c|c|}
\hline Category & $\begin{array}{l}\text { European } \\
(n=759)\end{array}$ & $\begin{array}{l}\text { Asian } \\
(n=247)\end{array}$ & $\begin{array}{l}95 \% \text { confidence } \\
\text { interval }{ }^{\star}\end{array}$ \\
\hline Wheeze & $19 \cdot 6$ & 11.9 & 2.9 to 12.5 \\
\hline Wheeze or SOB with exercise & $16 \cdot 2$ & $12 \cdot 7$ & -0.8 to 28.7 \\
\hline Night/early morning cough & $64 \cdot 2$ & $42 \cdot 3$ & $15 \cdot 1$ to $28 \cdot 7$ \\
\hline Diagnosed as asthmatic & $12 \cdot 0$ & $6 \cdot 2$ & $2 \cdot 1$ to $9 \cdot 5$ \\
\hline Taking medicines for asthma & $1 \cdot 1$ & $1 \cdot 5$ & -2.0 to 1.2 \\
\hline Visited doctor for wheeze & $12 \cdot 8$ & $9 \cdot 3$ & -0.7 to $7 \cdot 7$ \\
\hline Missed some school due to wheeze & $13 \cdot 2$ & $7 \cdot 5$ & 1.7 to 9.7 \\
\hline Admitted to hospital for wheeze & 0.9 & 0.7 & -1.0 to 1.4 \\
\hline \multicolumn{4}{|l|}{ Current wheeze: } \\
\hline Boys & 23.9 & $11 \cdot 7$ & $5 \cdot 2$ to $19 \cdot 2$ \\
\hline Girls & $15 \cdot 2$ & $12 \cdot 1$ & -3.4 to 9.6 \\
\hline $95 \%$ confidence interval ${ }^{\star} \dagger$ & $3 \cdot 1$ to $14 \cdot 3$ & $-8 \cdot 2$ to $7 \cdot 4$ & \\
\hline Families $\leqslant 4$ children & 23.9 & $12 \cdot 0$ & 0.5 to 13.3 \\
\hline Families $>4$ children & $18 \cdot 9$ & $12 \cdot 6$ & $-2 \cdot 3$ to $24 \cdot 9$ \\
\hline $95 \%$ confidence interval ${ }^{\star}+$ & -7.7 to 17.5 & -7.5 to 8.7 & \\
\hline
\end{tabular}

*For difference in proportions (European rate - Asian rate).

†For boys $v$ girls.

†For families with four children or less $v$ those with more than four children.

to be receiving drug treatment for asthma was similar in the two groups.

The prevalences of wheezing in the previous 12 months did not show a regular trend with age or socioeconomic group in either ethnic group. The ethnic specific prevalences of wheezing standardised by the socioeconomic distribution of the entire sample were similar to the crude prevalences (Europeans 19.4\%, Asians $12.9 \%$, confidence interval of difference $1.7 \%$ to $11.4 \%$ ). The prevalence of wheezing was similar among Asian children born in Britain $(12 \cdot 2 \%)$ and those born elsewhere $(11.8 \%)$, and both rates were lower than the prevalence of wheezing among British born Europeans.

Among European children wheezing was reported twice as commonly in boys as in girls, and more commonly, but not significantly so, in children from larger than smaller families (table 2). Among Asian children there were no significant differences by sex or by family size. The prevalence of reported wheeze was higher among children from Urdu speaking families $(11 / 56,19.6 \%)$ than among children from the other three language groups (Punjabi 13/157, $8.5 \%$; Bengali $10 / 29,10.3 \%$; Gujarati $2 / 15$, $13.3 \%)$. Wheeze was reported more commonly, but not significantly so, among 39 Asian children given a translation of the questionnaire $(18.9 \%)$ than among 235 Asians given only the English version $(10.8 \%(-5 \cdot 1 \%$ to $21 \cdot 3 \%)$ ).

Among children reporting wheeze in the previous 12 months (table 3 ), significantly more European than Asian children had been diag-

Table 3 Diagnosis, treatment, and medical attention among children reporting wheeze in previous 12 months

\begin{tabular}{|c|c|c|c|}
\hline Category (\% of ethnic group) & $\begin{array}{l}\text { European } \\
(n=148)\end{array}$ & $\begin{array}{l}\text { Asian } \\
(n=32)\end{array}$ & $\begin{array}{l}95 \% \text { confidence } \\
\text { interval }^{\star}\end{array}$ \\
\hline $\begin{array}{l}\text { Diagnosed as asthmatic } \\
\text { Taking medicines for asthma } \\
\text { Visited doctor for wheeze } \\
\text { Admitted to hospital for wheeze }\end{array}$ & $\begin{array}{r}54 \cdot 4 \\
52 \cdot 4 \\
65 \cdot 5 \\
4 \cdot 8\end{array}$ & $\begin{array}{r}31 \cdot 3 \\
31 \cdot 3 \\
78 \cdot 1 \\
6 \cdot 5\end{array}$ & $\begin{array}{r}5 \cdot 1 \text { to } 41 \cdot 1 \\
3 \cdot 1 \text { to } 39 \cdot 1 \\
-28 \cdot 8 \text { to } 3 \cdot 6 \\
-11 \cdot 0 \text { to } 7 \cdot 6\end{array}$ \\
\hline
\end{tabular}

^For difference in proportions (European rate - Asian rate). nosed as having asthma or were receiving treatment, but a slightly higher proportion of Asian children had visited their doctor or been admitted to hospital for wheeze.

\section{Discussion}

This study has been unable to reject the null hypothesis that asthma prevalence is no higher in Asian than in European children in Southampton, on the basis of any of the parameters measured, including reported asthma symptoms, diagnosed asthma, and indices of asthma morbidity. Furthermore, the failure to show a higher rate in Asians does not seem to be due to confounding by socioeconomic group. Asian children given a translated questionnaire reported more wheeze than those not given a translation, but the rate was still not higher than that in European children. Although the measured prevalence of asthma symptoms was actually lower in Asians, we did not find a higher rate, owing to the sampling and language difficulties, and the study hypothesis was stated in one sided terms.

In our study the prevalence of wheezing in the previous 12 months among European children $(19.6 \%)$ was considerably higher than that reported by Clifford et al among European children aged 7 and 11 years in Southampton $(12 \cdot 1 \%) .{ }^{10}$ The prevalence of wheezing among Asians was similar to prevalences of asthma documented by several studies of predominantly European children elsewhere in the United Kingdom. ${ }^{112}$ Lower rates than ours were reported for Asian children in two studies, ${ }^{56}$ and higher rates in another. ${ }^{7}$ The reasons for these variations are not known, but because the differences have not been in a constant direction environmental or methodological variation seems more likely than genetic differences.

Sampling was not random across all children of either ethnic group in Southampton, which may have given rise to some estimation error. We attempted to study all children in the main schools attended by Asian children, and the sampling ratio among Asian children was high, so the Asian sample was unlikely to be significantly biased on the main questions studied.

Sample bias may have contributed to the high prevalence of wheeze found in European children, as the European schools were selected to match the predominantly Asian schools for socioeconomic background and may therefore not be representative of all the European children in Southampton. It is less likely that the true prevalence of asthma among European children would have risen from $12 \cdot 1 \%$ to $19.6 \%$ since the study of Clifford et al. ${ }^{10}$ However, even if the rate found by Clifford $e t$ al is more representative of the true rate in European children, the prevalence of wheeze in Asians was no higher. Retrospectively calculated, the power of the study to detect a higher rate in Asian children was $85 \%$ if the true rates had been $13 \%$ in Europeans and $20 \%$ in Asians, as assumed in the initial calculations of sample size.

More European than Asian children report- 
ing current wheeze were diagnosed as having and being treated for asthma, but slightly more Asian than European had reportedly visited the doctor or been admitted to hospital for wheeze. If these findings are correct two possible explanations are suggested. Asian children with symptoms of asthma may not have the disease as well diagnosed and treated as similar European children and in addition or as a result suffer more morbidity or severe disease. Alternatively, Asian families may have a lower threshold for reporting and seeking medical attention for symptoms, which may not be as severe as those reported by Europeans and therefore receive less in the way of diagnosis and treatment. The first explanation could explain the impression gained by primary health care workers that they are seeing more asthma among Asian children, but in view of the limitations of the sample obtained and the small number in this subgroup of wheezers the findings must be regarded as tentative.

The finding in Europeans but not Asians that wheezing was reported more commonly among boys than girls is difficult to explain. The higher rate of reported wheezing among Asian children given a translation may be because more mothers were able to understand and complete the questionnaires with a translation: as the primary caregivers, mothers may perceive and report symptoms in their children more commonly than fathers. The difficulty in translating the word wheeze may have led to spurious positive responses to this question when translated. There is no easy way to ensure that responses are valid or comparable even if a translation is used, and for this reason we initially tried to use the English language questionnaire alone.

This study highlights some of the difficulties that confront epidemiologists trying to examine disease prevalence in ethnic minority groups compared with the ethnic majority. The problems include difficulty in ensuring that medical and other questions are understood and answered in a similar way by the two groups, even if a translation is used, difficulty in obtaining a good response on reissue of a questionnaire in a repeatability study, and difficulty in obtaining satisfactory objective verification of disease. There is a need for development of other modalities to circumvent these problems, such as a questionnaire assisted by a video, which is currently being investigated by various groups. ${ }^{13}$

We conclude that Asian children probably do not suffer from more asthma than their European counterparts in Southampton. The anecdotal impression among primary health care workers that they do may result from more severe and less adequately treated asthma among Asians, or from a lower threshold for seeking medical attention among Asians.

We thank the children and parents who participated in this study, and the principals of the participating schools for their help. We also thank Dr C Osmond and Mrs F Lampe for statistical advice. We acknowledge the help of Allen and Hanbury. PKP was supported by the Asthma Foundation of New Zealand. CDP and LS were final year medical students in the Faculty of Medicine, University of Southampton, when this study was undertaken.

1 Spears J. The prevalence of allergic disease in young Britishborn schoolchildren of different ethnic origin. JR Coll Gen Pract 1975;25:282-5.

2 Jackson SHD, Bannan LT, Beevers DG. Ethnic differences in respiratory disease. Postgrad Med J 1981;57:777-8.

3 Donaldson LJ, Taylor JB. Patterns of Asian and non-Asian morbidity in hospitals. $B M J$ 1983;286:949-51.

4 Smith JM, Harding LK, Cumming G. The changing prevalence of asthma in schoolchildren. Clin Allergy $1971 ; 1: 57-61$.

5 Smith JM. The prevalence of asthma and wheezing in children. Br J Dis Chest 1976;70:73-7.

6 Smith JM, Cooper SM. Asthma and atopic disease in immigrants from Asia and the West Indies. Postgrad Med $J$ 1981;57:774-6.

7 Johnston IDA, Bland JM, Anderson HR. Ethnic variation in respiratory morbidity and lung function in children. Thorax 1987;42:542-8.

8 Melia RJW, Chinnn S, Rona RJ. Respiratory illness and home environment of ethnic groups. BMJ 1988; 296:1438-41.

9 Ayres JG. Acute asthma in Asian patients: hospital admissions and duration of stay in a district with a high immigrant population. Br J Dis Chest 1986;80:242-8.

10 Clifford RD, Radford M, Howell JB, Holgate ST. Prevalence of respiratory symptoms among 7 and 11 year old schoolchildren and association with asthma. Arch Dis Child 1989;64:1118-25.

1 Hill RA, Standen PJ, Tattersfield AE. Asthma, wheezing and school absence in primary schools. Arch Dis Child 1989; 64:246-51.

12 Lee DA, Winslow NR, Speight ANP, Hey EN. Prevalence and spectrum of asthma in childhood. $B M J$ 1983; 286:1256-8

13 Shaw RA, Crane J, Pearce N, Burgess CD, Bremner P, Woodman $\mathrm{K}$, et al. Comparison of a video questionnaire with the IUATLD written questionnaire for measuring asthma prevalence. Clin Exp Allergy 1992;22:561-8. 